\title{
A China no âmbito da mudança climática. Negociações exteriores e políticas domésticas
}

\author{
JEFFERSON DOS SANTOS Estevo*
}

Artigo recebido: 15 de fevereiro de 2019

Artigo aprovado: 7 de julho de 2019

Doi: https://doi.org/10.12804/revistas.urosario.edu.co/desafios/a.7682

Para citar este artigo: Dos Santos Estevo, J. (2020). A China no âmbito da mudança climática. Negociações exteriores e políticas domésticas. Desafíos, 32(1), 1-27. https://doi. org/10.12804/revistas.urosario.edu.co/desafios/a.7682

\section{Resumo}

As mudanças climáticas, advindas do crescente aquecimento global, já são sentidas em diversas partes do planeta. A cooperação entre os Estados se faz necessária, para que as emissões de gases do efeito estufa diminuam, controlando o aumento da temperatura global. As negociações sobre mudança climática apresentavam uma divisão entre paises desenvolvidos e em desenvolvimento, sendo substituida pelo novo modelo em Paris, 2015. A China é ator central nas negociações e ao mesmo tempo, o maior emissor global destes gases. As emissões chinesas são em maior parcela advinda do setor de energia, que está baseado no carvão e no petróleo. O país indicou suas metas voluntárias em Copenhague, no ano de 2009, o que se mostrou como grande evolução a favor de sua politica climática. No ano de 2015, o país comunicou a Intenção $\mathrm{Na}$ cional Designada (NDC), que previa a redução da intensidade de emissões entre $60 \%$ e $65 \%$ em relação ao ano de 2005, e que $20 \%$ da matriz energética passaria a ser

\footnotetext{
* Doutorando em Ciências Sociais pela Universidade Estadual de Campinas (Unicamp) (São Paulo, Brasil). Correio eletrônico: j.s.estevo@gmail.com. orCID: https://orcid. org/0000-0002-1249-3493
} 


\title{
2 I Jefferson dos Santos Estevo
}

baseada em energia renovável, ambas metas seriam atingidas até o ano de 2030. As mudanças climáticas receberam atenção das políticas domésticas chinesas, sobretudo na reformulação da matrizenergética. O país apoia o princípio da responsabilidade comum, porém diferenciada, para manter sua política externa climática. O risco da mudança climática é presente no pais, que adotou a partir de 2007, políticas nacionais sobre o clima. O objetivo do artigo é realizar o levantamento das ações da China sobre mudança climática, tanto no âmbito interno, quanto internacional, no periodo incluido até o Acordo de Paris, 2015.

Palavras-chave: China, mudança climática, politica externa, energia.

\section{China in the Context of Climate Change. Foreign Negotiations and Domestic Policies}

\begin{abstract}
Climate change, stemming from growing global warming, is already being felt in many parts of the planet. Cooperation between states is needed to reduce greenhouse gas emissions in order to control the rise in global temperature. A divide between developed and developing countries characterizes climate change negotiations, which were replaced by a new model in Paris, 2015. China is a central actor in the negotiations as well as the largest global source of greenhouse gases. Chinese emissions are largely from the energy sector, based on coal and oil. The country indicated its voluntary targets in Copenhagen, 2009, which is understood as an evolution in its climate policy. In 2015, before COP 21, the country reported the National Designated Intent (NDC) of reducing emissions intensity by between $60 \%$ and $65 \%$ in relation to 2005 and basing $20 \%$ of the energy matrix on renewable energy, both by the year 2030. Climate change has received attention in Chinese domestic politics, especially in the reformulation of the energy matrix. The country supports the principle of common but differentiated responsibility to maintain its climate foreign policy. The risk of climate change is recognized in the country, which adopted national climate policies in 2007. The aim of the article is to survey China's actions on climate change, both internally and internationally, in the period up to the Paris Agreement, 2015.
\end{abstract}

Keywords: China, climate changes, foreign policy, energy. 


\title{
China en el ámbito del cambio climático. Negociaciones exteriores y políticas domésticas
}

\begin{abstract}
Resumen
El cambio climático, derivado del creciente calentamiento global, ya se siente en diversas partes del planeta. La cooperación entre los Estados es necesaria para que las emisiones de gases del efecto invernadero disminuyan, controlando el aumento de la temperatura global. Las negociaciones sobre cambio climático presentaban la división entre países desarrollados y en desarrollo, sustituida por el nuevo modelo en París 2015. China es actor central en las negociaciones y el mayor emisor global. Las emisiones chinas se derivan en mayor medida del sector de energía, basado en el carbón y en el petróleo. El país indicó sus metas voluntarias en Copenhague 2009, lo que es entendido como evolución en su política climática. En el año 2015, antes de la COP 21, el país comunicó la Intención Nacional Designada (NDC), reducción de intensidad de emisiones entre el 60\% y el 65\% en relación con el año 2005, y un $20 \%$ de la matriz energética basada en energía renovable, ambas hasta el año 2030. El cambio climático recibió atención en las políticas domésticas chinas, sobre todo en la reformulación de la matriz energética. Elpaís apoya el principio de la responsabilidad común, pero diferenciada, para mantener su política externa climática. El riesgo del cambio climático está presente en el país, que adoptó a partir de 2007 politicas nacionales sobre el clima. Elobjetivo del articulo es realizar el levantamiento de las acciones de China sobre cambio climático, tanto en el ámbito interno como internacional, en el periodo hasta el Acuerdo de París 2015.
\end{abstract}

Palabras clave: China, cambio climático, política externa, energía.

\section{Introdução}

As atividades humanas têm provocado o aumento das emissões dos gases de efeito estufa (GEE), que em níveis naturais mantêm a temperatura do planeta favorável a vida. As emissões dos gases estão conectadas a diversas áreas da economia global. O prevalecente é o setor de energia, seguido pelo agropecuário. A maior parcela da energia global é proveniente de fontes não renováveis, como o carvão e o petróleo. As grandes economias globais dependem dessas 
fontes, o que as tornam grandes emissoras de GEE, sobretudo países como a China, Estados Unidos e Índia. A redução das emissões de GEE é fundamental para não agravar o superaquecimento do planeta (Giddens, 2010).

As emissões de GEE são históricas, tendo início desde o começo da industrialização. Os países denominados desenvolvidos conheceram a industrialização muito antes dos países ainda em desenvolvimento. Portanto, suas emissões históricas de GEE são maiores. A primeira reunião global sobre mudança climática, ocorreu no Rio de Janeiro em 1992, e dividiu os países em dois blocos, pautado nas emissões históricas e grau de desenvolvimento de cada país. Os países em desenvolvimento não aceitaram possuir a mesma responsabilidade que os países desenvolvidos. Sobre essa divisão, ao final da Convenção-Quadro sobre Mudança do Clima (United Nations Framework Convention on Climate Change, UNFCCC), convenção estabelecida na Rio-92, estabeleceu-se um importante princípio, o qual define responsabilidade comum para os países, porém diferenciadas (Goldemberg, 2000; Viola, 2002).

Os Estados irão cooperar, em espírito de parceria global, para a conservação, proteção e restauração da saúde e da integridade do ecossistema terrestre. Considerando as diversas contribuições para a degradação do meio ambiente global, os Estados têm responsabilidades comuns, porém diferenciadas. Os países desenvolvidos reconhecem a responsabilidade que lhes cabe na busca internacional do desenvolvimento sustentável, tendo em vista as pressões exercidas por suas sociedades sobre o meio ambiente global e as tecnologias e recursos financeiros que controlam (Declaração do Rio, 1992).

O princípio tem norteado parte das negociações, no que tange a divisão das responsabilidades. Em todo o percurso das negociações, países em desenvolvimento mantêm o entendimento de não possuírem metas de mitigação (Winkler \& Rajamani, 2013; Pauw, et al., 2014). As negociações internacionais, no âmbito da mudança climática, obtiveram um novo capítulo no ano de 2015 , durante a $21^{\circ}$ Conferência das 
Partes (COP), em Paris. Um novo acordo, substituto do Protocolo de Quioto (COP 3) foi negociado e entrará em vigor a partir de 2020. A divisão ainda persiste, os países já desenvolvidos têm mais responsabilidades e, também devem financiar ações de mitigação nos países mais vulneráveis (Dimitrov, 2016; Falkner, 2016).

O Acordo de Paris detém a preocupação acerca do nível máximo de aumento da temperatura global. Os países negociaram um aumento máximo em até 2 Graus Celsius, com esforços para chegar a $1,5^{\circ} \mathrm{C}$. O IPCC lançou um relatório em 2018, com dados sobre o aumento da temperatura global em até, $1,5^{\circ} \mathrm{C}$, em comparação com os níveis pré-industriais. $\mathrm{O}$ documento foi apresentado como um pedido ao final da COP 21, relatando os impactos e riscos para um aumento da temperatura global de $1,5^{\circ} \mathrm{C}$ e $2^{\circ} \mathrm{C}$. O documento afirma que a temperatura global, em média, já subiu $1^{\circ} \mathrm{C}$, em comparação aos níveis pré-industriais, o aumento está entre 0,8 e $1,2^{\circ} \mathrm{C}$. O relatório expõe a urgência da conservação do aumento a um nível máximo de $1,5^{\circ} \mathrm{C}$ (IPCC, 2018).

Os relatórios do IPCC demonstram a influência da ação humana na elevação da temperatura global. Ao longo dos anos, o Painel produziu estudos sobre os riscos climáticos, como e em que intensidade os países serão afetados. $\mathrm{O}$ aumento da temperatura é diferente para cada região do planeta, ou seja, não é linear, sendo maior na superfície do que nos oceanos. O Painel também indica que em diversas regiões do planeta já está comprovado o aumento da ocorrência de eventos naturais extremos, como tempestades, secas, ciclones, elevação do nível do mar, entre outros. A incidência desses impactos depende da aplicação de medidas de mitigação e adaptação. As mudanças estão em curso, mas os riscos podem ser ainda maiores, caso tais medidas não sejam aplicadas. Nos cenários apresentados no Painel, a elevação em no máximo $1,5^{\circ} \mathrm{C}$ acarretaria menos riscos para o planeta (IPCC, 2018).

Segundo Beck (2009), risco é a percepção sobre um determinado acontecimento, não um fato real, presente. Sendo assim, cabe a cada ator ter a percepção do risco, o que impacta na adoção ou não de medidas para contê-los. No caso da mudança climática, a mitigação 


\section{6 / Jefferson dos Santos Estevo}

de GEE é uma das ações adotadas, reduzindo os riscos climáticos. A mudança climática é um risco global, afeta e afetará os países de diferentes maneiras, entretanto, todos serão afetados. Os riscos advindos da mudança do clima são analisados e enfrentados de diferentes formas por cada Estado. O tema ainda é visto como uma ameaça futura, postergando ações dos governos e da sociedade. A adoção de medidas no presente, que podem acarretar desconfortos no cotidiano, não é prioridade, pois o problema climático parece distante. Apesar de comprovados o aumento dos eventos climáticos, o pior cenário não está visível na vida cotidiana, o que não estimula ações imediatas (Giddens, 2010; Victor, 2016; Ferreira, 2017).

A cooperação entre os Estados é necessária para conter o aumento da temperatura global, com redução de emissão de GEE. Não importa a origem da emissão dos gases, pois a concentração desses na atmosfera traz consequências ao planeta inteiro, causando diversos problemas. Embora as responsabilidades sejam globais, apresentam diferenças por conta do histórico das emissões de cada país (UNFCC, 1992). As mudanças no clima global são um novo risco, ainda recente, resultante de processos de desenvolvimento tecnológico e científico. Segundo Ferreira (2017), os novos riscos pós-industriais não são totalmente conhecidos, seu alcance é global, não há forma de retroceder, são irreversíveis. O enfrentamento dos riscos necessita de ações dos Estados, ator principal nas negociações e capaz de adotar medidas de mitigação.

A cooperação entre os Estados é analisada de maneira distinta nas Relações Internacionais. Em nossa análise, a cooperação entre os Estados pode ocorrer, mesmo em um sistema internacional anárquico. A anarquia no sistema internacional, não obstrui a possibilidade de cooperação entre os Estados. As instituições internacionais podem influenciar nas decisões dos atores, auxiliando na cooperação e evitando renúncias. As instituições facilitam os acordos e convergências entre os Estados, que buscam interesses comuns e não apenas o interesse individual (Keohane, 1984; Stein, 1990; Le Preste, 2000). 
O âmbito doméstico é fundamental para o entendimento da cooperação internacional, assumindo importância nas tomadas de decisões durante as negociações no plano internacional. Em negociações internacionais, deve haver uma interação e um ponto de encontro entre os dois níveis (Putnam, 1988; Milner, 1997). Os interesses, políticas internas, a diversidade de atores, demandas de diferentes grupos; influenciam nas decisões no âmbito externo. A tomada de decisão no plano exterior é também resultado do entendimento de diferentes atores nacionais, convergência de interesses e demandas, nesse sentido, a análise do plano doméstico é essencial (Milner, 1992; Jervis, 1999). O entendimento da cooperação entre os Estados deve estar conectado com os interesses internos (Milner, 1992). As negociações internacionais sobre mudança climática estão pautadas em ambos os níveis, o doméstico e o internacional. Na análise de Keohane e Oppenheimer (2016) existe a combinação entre estratégias nas negociações internacionais e políticas domésticas. A formulação da política externa climática precisa considerar políticas e características internas.

A mitigação da mudança climática depende dos Estados. As transformações nas relações internacionais nos últimos anos, com ascensão de novos atores, também se refletem nas negociações climáticas e nos níveis de emissões. Os Estados Unidos foram os maiores emissores até 2007, sendo ultrapassados pela China. Em anos mais recentes, sobretudo após a crise financeira de 2008, países como Brasil, China, Índia, Rússia, África do Sul, México e Turquia, ascenderam no cenário econômico e político internacional (Viola, 2014; Stuenkel \& Taylor, 2015). No âmbito das negociações climáticas, no ano de 2008, Brasil, África do Sul, Índia e China formaram um grupo de negociadores, o BASIC. $\mathrm{O}$ aumento das emissões de GEE desses países refletiu na cobrança por metas de mitigação, os quais sempre foram contrários (Hallding, et al., 2013; Hochsteller \& Milkoreit, 2015; Bueno \& Pascual, 2016).

O nosso trabalho visa analisar o histórico da China sobre a mudança climática, indicando as principais ações internas e sua participação nas negociações climáticas internacionais. Em nosso entendimento, as mudanças domésticas influenciaram as negociações internacionais. $\mathrm{O}$ crescimento econômico demandou um elevado aumento 
no uso de energia, em sua maior parcela não renovável. A poluição e a mudança no clima têm causado problemas ambientais e riscos ainda não mensuráveis ao país. Para tanto, medidas foram tomadas. No plano internacional, com a ascensão da economia chinesa, o país retomou sua participação nas relações internacionais, como protagonista. Os planos domésticos indicam as metas de reduções no plano internacional. Os diferentes interesses nacionais pautam a formulação da política exterior climática.

A mudança do clima é um problema atual para a China. Os riscos provenientes deste cenário podem aumentar, o que causa preocupação aos líderes do país, já que são imensuráveis. A adoção de políticas de mitigação e adaptação é essencial. O plano doméstico está conectado as medidas internacionais, sendo que a política externa chinesa está fundamentada nas ações domésticas, influenciada pelos riscos climáticos. Assim, o presente artigo se articula com o auxílio da sociologia ambiental, e os riscos ambientais. E também, com as relações internacionais, no que tange os níveis de atuação, interna e externa. A mudança do clima acarreta riscos para a população, o que demanda políticas domésticas do Estado, as quais influem na política exterior. Busca-se trabalhar as dimensões nacionais e internacionais da questão climática, com análise de política externa e a percepção do risco, através do diálogo entre sociologia ambiental e as relações internacionais. Para tanto, é importante entender as ações de ambos nas negociações internacionais e também as políticas domésticas. A primeira parte do artigo apresenta o plano internacional, as ações chinesas nas negociações globais. A seção seguinte expõe o histórico das ações domésticas. Já a terceira parte, trabalha com os riscos e a relação entre plano doméstico e internacional, assim como as conclusões do artigo.

\section{O histórico da China nas negociações climáticas internacionais}

A participação chinesa na Conferência de Estocolmo, em 1972, marcou o início da atuação do país em negociações ambientais globais. 
Neste período, a China estava determinada em manter o crescimento econômico, reduzir a pobreza e manter as políticas implementadas pelo Partido Comunista (Bjørkum, 2005). A Conferência de Estocolmo marcou a divisão entre os dois blocos; os países em desenvolvimento argumentaram que os danos ambientais eram causados pelas ações históricas dos países já desenvolvidos. A China, o Brasil e a Índia reafirmaram o direito ao desenvolvimento e preservação da soberania para ações ambientais; com o intuito de erradicar a pobreza (Duarte, 2003). O alinhamento com os países em desenvolvimento sempre fez parte da política externa chinesa no âmbito das negociações climáticas (Bjørkum, 2005; Stendal, 2014).

A China é o principal país do Grupo G-77 + China, que atua nas negociações internacionais e possui um vasto número de países, com diversos interesses. O grupo foi formado anos antes, em 1967, durante a Conferência das Nações Unidas sobre Comércio e Desenvolvimento. Os membros fundadores eram 77 , atualmente o grupo conta com 134 países. O bloco participa ativamente das negociações na Organização das Nações Unidas (ONU), em diferentes tópicos (Hallding, et al., 2013; Hochstetler, 2012; Saran \& Jones, 2017).

No plano das negociações climáticas o G-77 é o maior grupo negociador, com diferenças entre os membros. O grupo engloba países como a China e Índia, grandes economias e grandes emissores de GEE. No grupo, também há países exportadores de petróleo: Arábia Saudita, Qatar, Nigéria e Emirados Árabes. No mesmo grupo, estão os países mais afetados pela mudança climática: Moçambique, Filipinas, Tailândia e Fiji. A linha geral que os une está no "princípio das responsabilidades comuns, porém diferenciadas". Estes países adotaram, desde o início das negociações climáticas, o posicionamento de que os países já desenvolvidos devem agir no combate à mudança climática e que têm o direito ao desenvolvimento, sem esforços de mitigação (Hallding, et al., 2013; Hurrel \& Sengupta, 2012).

Durante a Rio-92, a política externa chinesa manteve o alinhamento com o Grupo 77+ China, priorizando o desenvolvimento econômico 
e social, participando ativamente para a adoção do princípio da responsabilidade histórica. No período da Rio-92, o país buscava retomar sua participação no cenário internacional, que estava desgastado devido as condenações internacionais do episódio em Tiananmen. O país estava isolado e a participação nas negociações climáticas internacionais era vista como uma ponte para retornar ao sistema internacional (Chen, 2008).

As negociações climáticas continuaram durante as Conferências das Partes (COP). Em 1997 os países chegaram ao primeiro acordo global, o Protocolo de Quioto, mantendo a divisão entre os países. Os EUA reiteravam a participação, mesmo que voluntária, dos países em desenvolvimento, sobretudo Índia e China. Ao final da terceira conferência, ficaram estabelecidos três Mecanismos de Flexibilização, com o intuito de auxiliar nas medidas de mitigação. O terceiro, o Mecanismo de Desenvolvimento Limpo (MDL), contava com a participação dos países em desenvolvimento, através de projetos de redução de emissões em diversos setores (Bjørkum, 2005).

No início, a China se mostrou contrária aos mecanismos de flexibilização, pois com uma possível redução obrigatória, no futuro, as reduções de emissões já teriam sido realizadas através de projetos de MDL. Assim, teria vendido os projetos mais baratos de mitigação, no futuro seria difícil alcançar as metas, o que demandaria investimento em novas tecnologias. Porém, essa postura foi modificada com a ratificação chinesa do Protocolo de Quioto. No âmbito interno, houve um melhor entendimento dos ganhos com projetos de MDL. A China até então cética em relação aos mecanismos, modifica seu posicionamento e passa a apoiá-los, principalmente diante da possibilidade de investimentos e transferência de novas tecnologias para o país (Zhang, 2003; Zhang, 2013; Stendal, 2014). A implementação de projetos de MDL foi importante em níveis municipais e provinciais, no financiamento de instalações de energias renováveis. A China é o país com maior número de projetos, o que beneficiou o país com investimentos externos, o ganho com a negociação dos créditos de carbono e também com a redução das emissões (Bluemling \& Mol, 2013; Barbi, 2016). 
A crise financeira global, em 2008, afetou em menor escala alguns países, tratados como emergentes. A China se destacou com um PIB crescente e passou a ocupar a posição de segunda maior economia do mundo. O Brasil, a Índia e a Rússia também figuravam com bons índices econômicos. Este grupo de países ficou reconhecido como BRIC (Brasil, Rússia, Índia e China), por um estudo em 2001 de Jim O’Neill, pesquisador do grupo financeiro Goldman Sachs. Segundo o estudo, China e Índia seriam líderes globais na distribuição de bens e serviços, enquanto Rússia e Brasil como fornecedores de matéria-prima (Stuenkel \& Taylor, 2015).

Os países dos BRICS, sem a participação russa, formam o grupo BASIC nas negociações climáticas globais. As equidades nos posicionamentos e interesses comuns contribuíram para a coesão entre os países do BASIC. $\mathrm{O}$ alinhamento do grupo poderia fortalecer as negociações internacionais e auxiliar nas demandas domésticas. O ponto central para o BASIC está na maior responsabilidade dos países desenvolvidos, pelo histórico de emissões. O aumento dos riscos climáticos é causado pela ausência de políticas de mitigação dos países desenvolvidos, estes portanto, devem assumir metas de reduções mais ambiciosas que os demais. Os países do BASIC adotam o princípio das "responsabilidades comuns, porém diferenciadas", entendendo a necessidade do desenvolvimento para os países do Sul (Hadlling, et al., 2013; Flemes \& Saraiva, 2014; Stuenkel \& Taylor, 2015).

O grupo recebeu destaque nas negociações da COP 15 em Copenhague, em 2009. O Protocolo de Quioto deveria ter sido revisado, já que seu prazo se encerraria em 2012. O BASIC sempre esteve alinhado com as decisões do G-77 + China, mas nessa COP, devido ao protagonismo no cenário internacional e nas negociações climáticas, Brasil, China, Índia e África do Sul tomaram a liderança. O crescimento das emissões demandava desses países uma participação mais ativa na mitigação de GEE. Porém, ainda alinhados nas responsabilidades históricas, estes países negavam medidas obrigatórias, relegando-as aos países desenvolvidos (Abranches, 2010; Handlling, et al., 2011; Zhu, 2015). 
O entendimento de que ações eram necessárias para diminuição da mudança climática, fez com que os países do BASIC adotassem medidas voluntárias de reduções de emissões, a Ação de Mitigação Nacionalmente Apropriada. Os países demonstraram quais eram suas medidas, suas políticas nacionais para mitigação e indicaram os valores que poderiam reduzir de suas emissões até 2020. A adoção por parte desses países de metas voluntárias foi uma mudança em suas políticas exteriores, sempre contrárias a qualquer meta e medida de reduções de emissões (Abranches, 2010; Hochsteler \& Milkoreit, 2015). A crescente participação nas relações internacionais, o aumento das emissões e a preocupação com a mudança climática, levaram estes países a reverem seus posicionamentos.

No ano de 2006 a China se tornou o país com maiores níveis de emissões de GEE, ultrapassando os EUA. Os índices amplia rama pressão internacional para que a China adotasse medidas de redução de emissão. A adoção de metas na COP 15 , mesmo que voluntárias, demonstra a evolução da política externa chinesa, contrárias a qualquer medida de mitigação (Barbi, et al., 2016). A divulgação em Copenhague foi o primeiro compromisso internacional chinês nas negociações do clima, no qual o país reduzirá sua intensidade de carbono (emissão de $\mathrm{CO}_{2}$ por unidade de PIB) entre $40 \%$ e $45 \%$, até 2020 , comparado aos níveis de emissões de 2005. A China também indicou políticas de substituição de até $15 \%$ de sua energia por fontes renováveis, até 2020 (Hung \& Tsai, 2012; Yu \& Zhu, 2015). As metas refletem a preocupação e urgência que o tema tem levantado internamente no país (Zhang, 2013; Ferreira \& Barbi, 2013; Barbi, 2016). A ativa participação chinesa em Copenhague aponta o desejo do país em ser ator central nas negociações climáticas, aspirando influenciar demais temas das relações internacionais (He, 2010; Conrad, 2012).

Os presidentes Barack Obama e Xi Jinping, assinaram um acordo climático bilateral em 2014. No acordo, os EUA indicaram a redução de GEE entre $26 \%$ e $28 \%$ até 2025 . A China, por sua vez, chegará ao pico de suas emissões até 2030, com esforços para alcançar a meta antes. Para tanto, deverá ter uma matriz energética composta por fontes 
renováveis em $20 \%$, também até 2030 . Os dois países são os principais emissores, e passaram a investir nos últimos anos, em energias renováveis (Basso \& Viola, 2016; Zhang, 2016). O acordo enfatiza as responsabilidades históricas e as capacidades domésticas de cada país. Os presidentes ressaltaram a importância do multilateralismo e também da nova parceria bilateral em um acordo, no ano seguinte, em Paris. $\mathrm{O}$ acordo destacava a urgência dos riscos climáticos e a necessidade de transição para uma economia verde, baseada em energias renováveis (White House, 2015).

A COP 20 ocorreu em Lima, também em 2014, sendo de suma importância para as negociações, e antecedeu a COP 21. Os países concordaram em indicar suas contribuições nacionais de mitigação, antes do início das negociações em Paris. As Intended Nationally Determined Contributions (INDCs) são indicações de contribuições de cada país, para combater o aquecimento global. Todos os países indicaram quais ações consideravam viáveis, com base no cenário social e econômico local. A adoção das INDCs nas negociações demonstrou a mudança em referência ao acordo de Quioto, onde todos os países participam e as metas não são juridicamente vinculantes, ou obrigatórias (Zhang, 2015; Bodansky, 2016).

$O$ acordo firmado entre os dois maiores emissores foi um sinal positivo antes da COP $21 \mathrm{em}$ Paris. A INDC deveria ser enviada para a UNFCCC um ano antes da conferência, a China foi um dos primeiros países, o que indicou a transição positiva em sua política externa climática, sendo mais ativa. Assim como apontado no acordo com os EUA, a China propôs uma mudança da matriz energética baseada em energias renováveis até 2030 , e sua INDC também propôs reduções de emissões, por unidade de PIB, entre $60 \%$ até $65 \%$ em relação ao ano de 2005. A INDC, ainda propõe uma porcentagem de $20 \%$ de fonte renováveis na energia primária e um aumento das áreas florestais (China, 2014). O presidente Xi Jinping anunciou as medidas na COP 21, o que é um marco na política externa chinesa. Jinping foi o primeiro presidente a participar de uma COP, antes representada por primeiros ministros, ou ministros de diferentes áreas (Gao, 2016). 
O acordo de Paris, negociado ao final da COP 21, visa manter o aumento da temperatura média global abaixo de $2^{\circ} \mathrm{C}$, tendo como base os níveis pré-industriais, e maiores esforços para limitar o aumento da temperatura em $1,5^{\circ} \mathrm{C}$, também acima dos níveis pré-industriais. $\mathrm{O}$ acordo demonstrou que eram necessárias modificações no processo de negociações, pois os grandes emissores rejeitaram as metas obrigatórias. O novo acordo abrange todos os países, onde cada parte deveria indicar sua INDC. As capacidades nacionais de mitigação são bases para os compromissos, respeitando a soberania de cada país. Apesar da indicação da INDC de diversos países, as atuais reduções são insuficientes para alcançar a meta de não aumento da temperatura global (Selin, 2015; Goldemberg \& Guardabassi, 2015).

Segundo análise de Li (2016), não obstante o acordo entre EUA e China, a divisão entre os dois blocos de países permaneceu nas negociações. A China desejava um novo acordo para substituir o de Quioto. Índia e China se comprometeram em reduzir suas emissões, como indicavam suas INDC, respeitando o direito de crescimento econômico, sem imposições de metas. Naquele momento, havia o entendimento de que China e Índia, grandes emissores, deveriam cortar suas emissões. Os negociadores chineses reiteraram a continuação do "princípio das responsabilidades comuns, porém diferenciadas”, exigindo esforços dos países desenvolvidos. A transferência de tecnologia e financiamentos, também seguiam na pauta dos chineses. Ainda segundo o autor, a China foi voz ativa nas negociações, o que indicou a importância do país nas negociações climáticas globais, e também, o papel central da China nas relações internacionais.

\section{As políticas domésticas no âmbito da mudança climática}

A preocupação ambiental passou a receber atenção ainda na década de 70 , entretanto o crescimento econômico ainda era o centro da política chinesa. A crescente poluição nas cidades recebeu espaço na década de 90 , com divulgação deste e demais problemas ambientais por jornalistas e acadêmicos. O governo entendeu a relevância da degradação 
ambiental, após anos de crescimento econômico baseado em energias não-renováveis (Li, 2016). No início dos debates internacionais sobre o aquecimento global e a mudança climática, a China, no final da década de 80, tratava o tema como estritamente científico. Em 1987 foi criada a State Science and Technology Commission founded the Chinese National Climate Committee, com o intuito de promover pesquisas na área. Em 1990 o tema ganhou relevância, com a participação de setores importantes do governo central, sendo estabelecido um novo órgão, o National Climate Change Coordination Group (NCCCG) (Stendal, 2014).

Neste mesmo ano, as questões sobre mudança climática ganharam ainda mais importância dentro do governo chinês, o NCCCG foi renomeado para National Leading Groupto Address Climate Change (NLGACC). A primeira ação contra a mudança do clima foi criada em 2007, o National Climate Change Program. O programa estava voltado para implementação de estratégias de eficiência energética, reflorestamento e investimento em energias renováveis. Algumas metas foram listadas para o ano de 2010, como a implementação em até $10 \%$ de energias renováveis e o reflorestamento de 20\% (Stendal, 2014; Barbi, et al., 2016). O documento oficial do programa demorou dois anos para ser elaborado, descrevendo o problema da mudança do clima para o país, suas políticas domésticas e posicionamento internacional. Ele indica a mudança climática como um problema ambiental e de desenvolvimento, substancialmente um problema de desenvolvimento, o que assinala a prioridade no crescimento econômico, em detrimento do meio ambiente (Chen, 2008).

O governo central é o responsável pela política interna e externa no âmbito climático. No âmbito interno, o NDRC é considerado o ator mais importante, que analisa a mudança climática sobre questões energéticas e econômicas. O NDRC tem como prioridade o crescimento econômico e o cuidado com o setor energético. As decisões do NDRC influenciam as políticas internas e externas chinesas sobre o clima (Barbi, 2016). Outro ator importante no âmbito climático é o Ministério das Relações Exteriores (MRE), que sustenta o alinhamento com as posições do Grupo77 + China. Alguns outros ministérios completam a articulação nacional sobre o clima, o Meteorological Administration 
(CMA), responsável por questões técnicas sobre o clima, Ministry of Science and Technology (MOST), sua função está bastante ligada ao MDL e novas tecnologias e o State Environmental Protection Administration, preocupado com as questões ligadas ao meio ambiente na China (SEPA) (Bjørkum, 2005).

Em 2005 foi adotada a Lei de Energias Renováveis, com o intuito de diminuição do uso de carvão, causador da poluição nas grandes cidades. A lei visava a expansão de energia solar, hidrelétrica e eólica, mas não com o intuito de mitigação (Stendal, 2014). A preocupação com o setor energético e os problemas ambientais são fatores centrais para a economia chinesa. Após a crise financeira de 2008, o país adotou um novo processo denominado "new normal". Um novo modelo de crescimento era necessário, menor em valor, mas com melhor qualidade, destacando a redução da desigualdade, inovação tecnológica e preocupação ambiental (Hilton \& Kerr, 2016; Li, 2016; Green \& Stern, 2017).

O Décimo Primeiro Plano Quinquenal propôs uma meta de redução de $20 \%$ na intensidade energética entre 2006 e 2010. O setor energético é o principal responsável pelas emissões chinesas. As empresas com maiores consumos energéticos, 1008 no total, foram obrigadas a reduzir o consumo energético. As medidas tiveram efeito e o resultado foi a redução da intensidade energética em 19,1\%, em 2010. A redução na intensidade de energia colaborou também para a redução de emissões. O $11^{\circ}$ Plano foi o primeiro a citar a mudança do clima (Barbi, et al., 2016; Barbi, 2016; Vieira, 2017). O $12^{\circ}$ Plano (2011-2015) mencionou, pela primeira vez, a redução de intensidade de carbono na economia. A meta do Plano era o acréscimo da utilização de energia renovável de $11,4 \%$, redução em $17 \%$ da intensidade de carbono na economia e 16\% na intensidade energética (Zhang, 2016; Barbi, 2016). A China implementou diferentes programas e políticas relacionadas a mudança do clima, principalmente no âmbito energético. $\mathrm{O} 11^{\circ}$ e $12^{\circ}$ demonstraram a preocupação com a mudança do clima, o setor energético e a poluição. 
O $13^{\circ}$ (2016-2020) é primordial para continuidade da modificação da matriz energética e a elevação da preocupação ambiental (Zhang, 2015). O plano visa: a implementação de $15 \%$ de energia renovável até 2020 e $20 \%$ até 2030 , na matriz energética; o aumento na utilização de energia eólica e mare motriz; desenvolvimento e liderança na pesquisa de energias renováveis; e redução da participação de empresas estrangeiras nas empresas energéticas (IEA, 2018). O $13^{\circ}$ Plano possui uma seção para mudança climática, enfatizando a importância de políticas de mitigação de GEE e adaptação. A China controlará as emissões de GEE em diferentes setores da economia, principalmente nas indústrias de geração de energia, aço e química. O país deve ainda, implementar um sistema de negociações de emissões e construir novas indústrias sem emissões de GEE (China,2014).

Os planos quinquenais indicam as ações do país sobre diferentes temas. A partir do $11^{\circ}$, a regulação da energia recebeu relevância. Nos seguintes, a questão da mudança do clima foi indicada, em conexão com a modificação da matriz energética. O avanço da economia chinesa demandou investimentos rápidos em energia, por consequência, a questão energética é fundamental para a China. Além da demanda crescente, suas emissões de GEE são em maioria provenientes do setor energético (Zhang, 2015, Barbi, et al., 2016). A China é o maior consumidor e produtor global de energia, sendo principalmente provenientes de fontes não renováveis. A China também é o país que mais investe e modifica sua matriz energética por fontes renováveis. Devido a questões econômicas e também ambientais, o país tem aplicado mudanças, sobretudo em energia eólica e solar, assim como avanços significativos na eficiência energética. O país é o maior produtor de carvão, responsável por $45 \%$ do total mundial, o maior produtor de eletricidade, também o principal país produtor de energia hidrelétrica, representando cerca de $20 \%$ da produção mundial (Basso \& Viola, 2014). 


\section{Considerações finais}

Os relatórios do IPCC contribuem para a redução das incertezas sobre a mudança climática. Os riscos climáticos estão associados com o futuro, um problema para as próximas gerações. Porém, as medidas devem ser tomadas no presente, para limitar os riscos (Barret, 2007). A mudança climática ainda é observada como uma ameaça futura, postergando ações dos governos e da sociedade. A adoção de medidas no presente, que podem acarretar desconfortos no cotidiano, não é prioridade, pois o problema climático parece distante. Os perigos não são palpáveis e nem visíveis na atualidade, não em sua maneira extrema, o que adia ações de mitigação (Giddens, 2010; Barbi, 2016).

O conhecimento sobre a mudança do clima é vasto, as evidências científicas estão demonstradas, porém faltam políticas e ações efetivas, para redução, prevenção e precaução dos riscos. O resultado do avanço dos estudos colabora com maior conhecimento sobre os riscos futuros, e tal conhecimento agrava a percepção do risco (Barros-Platiau, et al., 2004; Barbi, 2016). No âmbito da mudança climática as evidências científicas avançaram, mas os riscos ainda são incalculáveis. $\mathrm{O}$ conhecimento sobre o tema é abrangente, porém faltam progressos em ações de mitigação e adaptação ao problema (Inoue, 2016; Ferreira, 2017).

A China é um dos países mais vulneráveis às mudanças climáticas (Barbi, et al., 2016; Ferreira, 2017; Pink, 2018). As regiões com maior desenvolvimento econômico estão na área costeira, que sofrerão com o aumento no nível dos oceanos. Outra preocupação com a mudança no clima está na agricultura. A China é um país bastante dependente de seu setor agrícola, alterações climáticas afetarão as regiões agrícolas, impactando na produção de alimentos. Eventos climáticos extremos também podem ocorrer, ocasionando falta de chuvas, causando dificuldades para as hidrelétricas do país e distribuição de água para as populações. Além da falta de chuvas, eventos extremos causarão mais desastres naturais, como desertificação e aumento de tempestades. Os conflitos internos também podem se acirrar, devido à escassez 
de recursos, como água, alimentos e energia (Lewis, 2009; Hung \& Tsai, 2012; Pink, 2018).

As emissões chinesas ainda são elevadas, representando $30 \%$ da emissão global. O setor de energia, baseado no carvão, é o grande responsável. Após anos de crescimento nas emissões, houve redução de 0,7 \% na comparação entre os anos de 2014 e 2015, diferente do crescimento de 9\% em média entre 2002 e 2011 (Olivier, et al., 2016). As recentes transformações no setor de energia, como investimento em recursos renováveis e melhoria da eficiência energética, têm ajudado o país a alcançar suas metas de reduções de emissões. $O$ país conviveu com o aumento da poluição ambiental, o que trouxe problemas para a saúde da população. A necessidade de evitar o pior cenário levou a tomada de diversas medidas para controle da poluição (Ferreira \& Barbi, 2013). A transição para uma economia sustentável, deve servir de exemplo para os demais países, como um exemplo de que é possível crescer economicamente e também preservar o meio ambiente. A gestão do presidente Xi Jiping tem demonstrado a preocupação com o desenvolvimento sustentável (Green \& Stern, 2017).

O uso do carvão causa elevada concentração de gases poluentes nas principais cidades chinesas. A poluição se tornou um grave problema para o governo chinês, que tem adotado medidas para combatê-la nos últimos anos. Junto ao carvão para geração de eletricidade, também ocorreu o aumento da frota de veículos, o que trouxe problemas de saúde para a população das grandes cidades. A pressão interna por melhores condições de saúde vem crescendo no país. Por outro lado, a China precisa manter o crescimento econômico, o que necessita de energia (Zhang, 2015; Vieria, 2017). A utilização do carvão como principal fonte energética, se explica com os dados das reservas nacionais. Segundo Vieria (2017): “Ao lado do 'fator trabalho', o uso do carvão em larga escala garantiu que os insumos energéticos e a eletricidade tivessem seus custos reduzidos, de modo a garantir o barateamento dos produtos finais, dessa forma, sua competitividade no mercado mundial" (p. 190). 
No que tange a política externa chinesa, ocorreu uma transição entre os dois últimos governantes, Hu Jintao e Xi Jinping. Após a crise internacional de 2008, a China, em conjunto com os países denominados BRICS (Brasil, Rússia, Índia, China e África do Sul) despenhavam um papel de destaque no cenário global, ganhavam espaço e influencia em diferentes negociações internacionais (Stuenkel \& Taylor, 2015). No período Hu Jintao (2003 a 2013), houve crescimento da participação chinesa no cenário internacional, com uma política externa assertiva, e o intuito de manter o crescimento econômico. A China assumiu a segunda colocação como economia, o que recolocou o país como importante potência regional e global. O presidente Xi Jinping manteve uma política externa assertiva, mas elevando a importância das relações internacionais para o país. A China não apenas participa das negociações internacionais, mas tem poder de influência em temas de seu interesse, no mesmo patamar dos EUA (Liao, 2016; Ferdinand, 2016).

No âmbito da política externa climática, existe uma continuidade. A soberania e o desenvolvimento do país, somado ao princípio das responsabilidades históricas; embasam o posicionamento chinês ao longo das negociações. A política externa chinesa ainda é pautada na defesa de maior participação dos países desenvolvidos, transferência de tecnologia e financiamento internacional (Hung \& Tsai, 2012; Stendal, 2014; Yu \& Zhu, 2015; Zhang, 2015; Moreira \& Ribeiro, 2017). Assim como outros temas importantes, a mudança climática deve avaliar o plano doméstico e internacional, e a harmonia entre as políticas nacionais e internacionais. A China, sobretudo após 2007, tem avançado em políticas domésticas de mitigação e vem ampliando sua participação nas negociações externas, o que a torna um país-chave. O país preza por sua autonomia interna, soberania e aumento de sua participação nas relações internacionais (Chen, 2008; He, 2010).

Alguns eventos climáticos já estão em curso, porém conforme o Paradoxo de Giddens, os perigos não são palpáveis e nem visíveis na vida cotidiana, não estimulando ações imediatas. Mas esperar para agir pode ser uma ação tardia, pois reverter o aquecimento do planeta dependerá de ainda mais ações. A mudança climática ainda 
é vista como uma ameaça futura, postergando ações dos governos e da sociedade (Giddens, 2010). Os riscos da mudança climática são imensos para a China, sua preocupação com o desenvolvimento e erradicação da pobreza também, cabe ao Partido Comunista coordenar a relação saudável entre o crescimento econômico e os riscos ambientais, advindos do aquecimento global. O tema climático é recorrente nos recentes Planos Quinquenais, o que indica a crescente preocupação com o tema (Moreira \& Ribeiro, 2017).

As negociações sobre mudança climática ocorrem no plano internacional, durante as COP. O tema é um desafio abrangente que demanda ações nos diferentes níveis e setores da economia. O plano doméstico é fundamental, sendo responsável pelas políticas de mitigação e adaptação. No caso chinês, os níveis estaduais e municipais são fundamentais, por serem responsáveis por grande parte das políticas nacionais. As políticas de mitigação são reguladas pelo governo federal e pelas províncias, respeitando e atendendo as características locais. As políticas de mitigação de GEE devem estar conectadas com diversos setores da sociedade, entendendo seus riscos, os custos e as dificuldades (Bulkeley \& Newel, 2010; Barbi, et al., 2016; Inoue, 2016).

A China se apresenta como ator central nas negociações climáticas (Moreira, 2015; Basso\& Viola, 2014; Ferreira, 2017). Ao longo dos anos tem a presentado evolução em alguns pontos, com a adoção de metas. Porém, sua política externa ainda é conectada aos países do Grupo 77+ China, os quais demandam investimentos dos países desenvolvidos, defendem as responsabilidades diferenciadas, a importância das emissões per capita, a soberania em decisões internas, reconhecimento internacional e o desenvolvimento econômico (Moreira, 2015; Ferreira \& Barbi, 2013; Moreira \& Ribeiro, 2017). Desde 2009, a China vem atuando nas negociações ao lado dos países do BASIC, por apresentarem demandas em comum. O princípio das responsabilidades diferenciadas é parte da política do BASIC, que sempre foram contrários a metas obrigatórias de redução (Zhu, 2015).

O âmbito doméstico é essencial para o entendimento da política externa chinesa. O risco climático, com agravamento dos problemas 
ambientais, trouxe preocupação ao governo chinês. A redução da pobreza e o crescimento econômico são primordiais para a China. O tratamento da mudança climática perpassa na combinação entre desenvolvimento e proteção ambiental. No caso chinês, na reformulação da matriz energética, baseada em fontes não renováveis. Ao longo dos últimos anos, o país tem investido na reformulação da sua matriz energética, reduzindo o consumo de carvão e promovendo o uso de fontes renováveis. A transição tem como preocupação a não redução do crescimento econômico, tendo sempre como meta a redução da pobreza e melhorar as condições de vida da população.

No plano internacional, a saída dos EUA do Acordo de Paris encaminha a China para a liderança das negociações. A efetiva participação chinesa nas negociações internacionais deve ser entendida como estratégia para a resolução dos problemas ambientais domésticos e sua segurança energética. O desenvolvimento econômico ainda é fator central para China, e aliar a redução dos riscos climáticos com seu crescimento econômico, exige investimentos em renovação e modificação energética. A política climática chinesa deve ser observada no âmbito doméstico e internacional, pois ambos os níveis estão relacionados. O risco climático trouxe a preocupação acerca do tema, fazendo com que o governo formulasse políticas de mitigação. As políticas de mitigação, através dos Planos Quinquenais, elaboraram metas de reduções de emissões de GEE e de investimentos em eficiência energética. Os Planos serviram como base para a formulação das metas chinesas nas negociações internacionais. As metas indicadas na COP 15 e 21 estão relacionadas com as capacidades domésticas, e os possíveis esforços do país na redução da emissão de GEE.

\section{Referências}

Abranches, S. (2010). Copenhague antes e depois. São Paulo: Civilização Brasileira.

Barbi, F. (2016). Governing climate change in China and Brazil: mitigation strategies. Journal of Chinese Political Science, 21(3), 357-370. https:// doi.org/10.1007/s11366-016-9418-y 
Barbi, F., Ferreira, L. \& Gou, S. (2016).Climate change challenges and China's response: mitigation and governance. Journal of Chinese Governance, 1(2), 324-339. https://doi.org/10.1080/23812346.2016.1181598

Barret, S. (2007). Why cooperate? The incentive to supply globalpublic goods. Oxford: Oxford University Press.

Basso, L. \& Viola, E. (2014). Chinese energy policy progress and challenges in the transition to low carbon development, 2006-2013. Revista Brasileira de Politica Internacional, 57(special edition), 174-192. https:/ / dx.doi.org/10.1590/0034-7329201400211

Basso, L. \& Viola, E. (2016). Wandering de carbonization: the BRIC countries as conservative climate powers. Revista Brasileira de Politica Internacional, 59(1), e001. https://dx.doi.org/10.1590/0034-7329201600101

Beck, U. (2009). World at risk. Cambridge: Polity Press.

Bjørkum, I. (2005) China in the international politics of climate change: a foreign policy analysis. FNI Report 12/2005. The Fridtjof Nansen Institute.

Bluemling, B. \& Mol, A. (2013). Clean development mechanism implementation and additionality in China: an institutional analysis. In L. Ferreira \& J. Guilhon (Eds.), China and Brazil: challenges and opportunities (pp. 141-165). São Paulo: Annablume.

Bodansky, D. (2016). The legal character of the Paris agreement. RECIEL, 25, 142-150. https://doi.org/10.1111/reel.1215

Bueno, M. \& Pascual, G. (2016). International climate framework in the making: the role of the basic countries in the negotiations towards the Paris agreement. JANUS.NET, e-Journal of International Relations, 7(2), 121-140.

Bulkeley, H. \& Newell, P. (2010). Governing climate change (global institutions). New York: Routledge.

Chen, G. (2008). China's diplomacy on climate change. The Journal of East Asian Affairs, 22(1), 145-174.

China. (2014). China's policies and actions on climate change 2014. The National Development and Reform Commission.

Conrad, B. (2012). Reconciling the "Beijing climate revolution" and the "Copenhagen climate obstinacy". The China Quarterly, 210, 435-455.

Declaração do Rio de Janeiro. (1992). Estudos Avançados, 6(15), 153-159.

Dimitrov, R. (2016). The Paris Agreement on Climate Change: behind closed doors. Global Environmental Politics, 16(1), 1-11. https://doi. org/10.1162/GLEP_a_00361 
Duarte, L. (2003). Política externa e meio ambiente. Rio de Janeiro: Jorge Zahar Ed.

Falkner, R. (2016). The Paris Agreement and the new logic of international climate politics. International Affairs, 92(5), 1107-1125.

Ferdinand, P. (2016). Westward ho-the China dream and 'one belt, one road': Chinese foreign policy under Xi Jinping. International Affairs, 92(4), 941-957. https://doi.org/10.1111/1468-2346.12660

Ferreira, L. (2017). O desafio das mudanças ambientais globais no Antropoceno. In L. Ferreira (Org.), O desafio das mudanças climáticas: os casos Brasil e China (pp. 15-55). Jundiaí: Paco Editorial.

Ferreira, L. \& Barbi, F. (2013). Some issues about environmental concerns in Brazil and China (social justice and transitional societies). In L. Ferreira \& J. Guilhon (Eds.), China and Brazil: challenges and opportunities (pp. 141-165). São Paulo: Annablume.

Flemes, D. \& Saraiva, M. (2014). Potências emergentes na ordem de redes: o caso do Brasil. Revista Brasileira de Politica Internacional, 57(2), 214-232.

Gao, Y. (2016). China's response to climate change issues after Paris Climate Change Conference. Advances in Climate Change Research, 7(4), 235-240.

Giddens, A. (2010). A política das mudanças climáticas. São Paulo: UNESP.

Goldemberg, J. (2000). Mudanças climáticas e desenvolvimento. Revista Estudos Avançados, 14(39), 77-83.

Goldemberg, J. \& Guardabassi, P. (2015). Burden sharing in the implementation of the Climate Convention. Energy Policy, 81(C), 56-60.

Green, F. \& Stern, N. (2017). China's changing economy: implications for its carbon dioxide emissions. Climate Policy, 17(4), 423-442.

Hallding, K., Jürisso, M., Carson, M. \& Atteridge, A. (2013). Rising powers: the evolving role of BASIC countries. Climate Policy, 13(5), 608-631.

He, L. (2010). China's climate change policy from Kyoto to Copenhagen: domestic needs and international aspirations. Asian Perspective, 34(3), 5-33.

Hilton, I. \& Kerr, O. (2016). The Paris Agreement: China's new normal role in international climate negotiations. Climate Policy, 17(1), 48-58.

Hochsteller, K. \& Milkoreit, M. (2015). Responsibilities of power transitions: emerging powers in the climate change negotiations. Global Governance, 21, 205-226.

Hochsteller, K. \& Viola, E. (2012). Brazil and the politics of climate change: beyond the global commons. Environmental Politics, 21(5), 753-777. 
Hung, M. \& Tsai, T. (2012). Dilemma of choice: China's response to climate change. Revista Brasileira de Politica Internacional, 55, 104-124.

Inoue, C. (2016). Governança global do clima: proposta de um marco analítico em construção. Carta Internacional (USP), 11, 91-117.

Intergovernmental Panel on Climate Change (IPCC). (2014). Climate change 2014: mitigation of climate change. Cambridge: Cambridge University Press.

Intergovernmental Panel on Climate Change (IPCC). (2018). Summary for policymakers. In Global warming of $1.5^{\circ} \mathrm{C}$ (pp. 1-32). Geneva: World Meteorological Organization.

International Energy Agency (IEA). (2018). China 13 th renewable energy development five-year plan (2016-2020). National Development and Reform Commission (NDRC).

Jervis, R. (1999). Realism, neoliberalism, and cooperation: understanding the debate. International Security, 24(1), 42-63.

Keohane, R. O. (1984). After hegemony cooperation and discord in the world political economy. New Jersey: Princeton University Press.

Keohane, R. \& Oppenheimer, M. (2016). Paris: beyond the climate dead end through pledge and review? Politics and Governance, 4(3), 142-151.

Le Preste, P. (2000). Ecopolítica internacional. São Paulo: Editora Senac.

Lewis, J. (2009).Climate change and security: examining China's challenges in awarming world. International Affairs, 85(6), 1195-1213.

Li, A. (2016). Hopes of limiting global warming? China and the Paris agreement on climate change. China Perspectives, 1(105), 49-54.

Liao, N. (2016). China's new foreign policy under Xi Jinping. Article in Asian Security, 12(2), 82-91.

Milner, H. (1992). International theories of cooperation among nations: strengths and weaknesses: cooperation among Nations by Joseph Grieco. World Politics, 44(3), 466-496.

Milner, H. (1997). Interests, institutions, and information: domestic politics and international relations. Princeton: Princeton University Press.

Moreira, H. M. (2015). A nova geopolitica das mudanças climáticas: o papel de Estados Unidos e China (Tese de Doutorado, Universidade de São Paulo, São Paulo, Brasil).

Moreira, H. M. \& Ribeiro, W. (2017). A atuação da China no G-77, BASIC e BRICS nas negociações internacionais do clima. In L. Ferreira (Org.), 


\section{6 / Jefferson dos Santos Estevo}

O desafio das mudanças climáticas: os casos Brasil e China (pp. 57-83). Jundiaí: Paco Editorial.

Olivier, J. G. J., Janssens-Maenhout, G., Muntean, M. \& Peters, J. A. H. W. (2016). Trends in global CO emissions: 2016 report. The Hague: European Commission-Joint Research Centre (JRC)-Directorate C-Energy, Transport and Climate-PBL Netherlands Environmental Assessment Agency.

Pauw, P., Bauer, S., Richerzhagen, C., Brandi, C. \& Schmole, H. (2014). Perspectives on differentiated responsibilities. Discussion Paper Nº 6/2014. Bonn, GE: Deutsches Institut für Entwicklungs Politik.

Pink, R. (2018). Climate change crisis solutions and adaption for a planet in peril. Surrey-British Columbia, Canada: Springer International Publishing. Putnam, R. (1988). Diplomacy and domestic politics: the logic of two-level games. International Organization, 42(3), 427-460.

Selin, H. (2015). Diálogos sobre o clima na ONU em Paris: como chegamos aqui e o que esperar. Revista Politica Externa, 24(1).

Stein, A. (1990). Why nations cooperate. Cornell, Michigan: University Press. Stendal, I. (2014). Chinese climate-change policy, 1988-2013: moving on up. Asian Perspective, 38, 111-135.

Stuenkel, O. \& Taylor, M. (2015). Brazil on the global stage. Power, ideas, and the liberal international order. New York: Palgrave.

UNFCCC. (1992). United Nations Framework Convention on Climate Change. Recuperado de https://unfccc.int/files/essential_background/background_publications_htmlpdf/application/pdf/conveng.pdf

Victor, D. (2016). Toward effective international cooperation on climate change: numbers, interests and institutions. Global Environmental Politics, 6(3),90-103.

Vieira, L. (2017). A internalização paradoxal dos critérios de sustentabilidade na formulação das estratégias de China e Brasil para o setor energético. In L. Ferreira (Org.), O desafio das mudanças climáticas: os casos Brasil e China (pp. 167-193). Jundiaí: Paco Editorial.

Viola, E. (2002). O regime internacional de mudança climática e o Brasil. Revista Brasileira de Ciências Sociais, 17(50), 25-46.

Viola, E. (2014). The BRICS in the international system: very relevant countries, but a group of limited importance. In G. Lins Ribeiro, T. Dwyer, A. Borges \& E. Viola (Orgs.), Desafios sociais, politicos e culturais dos BRICS (pp. 383-391). São Paulo: ANPOcs. 
White House. (2015). U.S. China jointpresidential statement on climate change. The White House Office of the Press Secretary. Recuperado de https:/ obamawhitehouse.archives.gov/the-press-office/2015/09/25/uschina-joint-presidential-statement-climate-change

Winkler, H. \& Rajamani, L. (2013). CBDR \& RC in a regime applicable to all. Climate Policy Volume, 14(1), 102-121. https://doi.org/ 10.1080/14693062.2013.791184

Yu, H. Y. \& Zhu, S. (2015). Toward Paris: China and climate change negotiations. Advances in Climate Change Research, 6(1), 56-66.

Zhang, H. (2013). China and international climate change negotiations. In Welt trends online-dossier (pp. 1-20). Potsdam, Germany.

Zhang, Z. (2003). The forces behind China's climate change policy: interests, sovereignty, and prestige. In P. Harris (Org.), Global warming and East Asia (pp. 43-66). London: Routledge.

Zhang, Z. (2015). China's role in climate change negotiations, perspectives for COP 21. In Study-China's role in climate change (pp. 1-18). Berlin: Friedrich-Ebert-Stiftung-Department for Asia and the Pacific.

Zhang, Z. (2016). Are China's climate commitments in a post-Paris Agreement sufficiently ambitious. CCEP Working Paper 1607. Melbourne: Crawford School of Public Policy-The Australian National University.

Zhu, X. (2015). International ethics and governance for climate change amid the rise of BASIC countries. International Social Science Journal, 64(211-212), 55-74. 